\title{
Editorial
}

\section{The importance of registry for systematic review and clinical trial}

Vivian Soetikno

Check for updates

Currently, many medical journals recommend that research, both conducted on humans and experimental animals and research review articles, should be registered before the research is published. These provisions are required to reduce publication bias, such as only publishing positive study results, and ensure that all clinical trials are publicly visible prior to subject recruitment. ${ }^{1}$ Registering systematic review and clinical trial also help other researchers and funders to understand how many trials are carried out and how the intervention studied is evaluated. In addition, registering trials allows other researchers to trace the study starting from the recruitment of subjects to the study completion and publication and minimize excessive duplication of trials. $^{2,3}$

One of the crucial elements of a high-quality systematic review is developing a protocol which includes main objectives and methods used to assess the risk of bias and analysis. ${ }^{4}$ Registering protocol information which was written in advance of the reviews can be done through the International Prospective Register of Ongoing Systematic Reviews (PROSPERO). A minimum data set that should be reported for a registry of systematic reviews includes a research question, such as patients and population, intervention or exposure, comparison, and outcome; inclusion and exclusion criteria; methods used to assess the risk of bias and analysis; anticipated start date; investigators; source of funding; competing interests of authors; and date of registration. ${ }^{1,3}$ Thus, registering the protocol of systematic reviews and reporting the results according to the Preferred Reporting Items for Systematic Reviews and MetaAnalyses (PRISMA) guidelines are suggested to help the authors to improve their systematic reviews and meta-analyses reports and the journals' peerreviewers and editors to critically appraise the published systematic reviews.
Sometimes, changes between protocols and published reviews, such as adding or removing outcomes or modifying between primary and secondary outcomes, may result in review bias. In 2002, Silagy et $a^{5}$ examined 47 reviews that the protocol had been published before. They found that almost all reviews had a major change compared to that published protocol with the greatest change was in the methods section, followed by the introduction section such as objectives narrowing, additional of comparison or new outcome measures, broadening of the inclusion criteria, and narrowing of the exclusion criteria. ${ }^{5}$

The International Committee of Medical Journal Editors recommends that journals should only publish trials that have been previously registered. However, some journals sometimes do not follow this recommendation, including the high-impact journals. ${ }^{6}$ In this issue, the Medical Journal of Indonesia published two systematic reviews, namely Irawati et al ${ }^{7}$ and Irdam et $\mathrm{al}^{8}$ who conducted a systematic review based on the recommendations set in the PRISMA and MetaAnalyses statements. ${ }^{9}$ Unfortunately, those reviews were not prospectively registered at the PROSPERO. All searches of both reviews were conducted using PubMed, Google Scholar, and Cochrane. Irdam et al $^{8}$ limited their review to studies published between 2010 and 2020 about animals or humans with diabetic erectile dysfunction and written in English. The intervention was mesenchymal stem cells injection with a comparison of subjects without intervention or receiving placebo, which was evaluated for their functional and structural outcomes. In addition, Irawati et $\mathrm{al}^{7}$ limited their review to studies of randomized controlled trials and observational studies reporting platinum chain and gold weight implants surgery for paralytic lagophthalmos patients published between 1990 and 2020 and written in English. Both reviews conducted data extraction with similar data variables,

Copyright @ 2021 Author. This is an open access article distributed under the terms of the Creative Commons Attribution-NonCommercial 4.0 International License (http:// creativecommons.org/licenses/by-nc/4.0/), which permits unrestricted non-commercial use, distribution, and reproduction in any medium, provided the original author and source are properly cited. For commercial use of this work, please see our terms at https://mji.ui.ac.id/journal/index.php/mji/copyright. 
namely first author's surname, year of publication, study design, and level of evidence.

In fact, a systematic review that is well conducted, reported according to the PRISMA guidelines, and prospectively registered in PROSPERO can be generally considered scientific evidence of high-caliber compared to individual trials in terms of making decisions for the benefit of clinical practice and health policy. ${ }^{1}$ We believe that registering a systematic review in advance will promote transparency, avoid bias, and improve methodological standards. Besides, registering a systematic review in advance only takes $30 \mathrm{~min}$ to complete of 22 questions.

From Medical Journal of Indonesia; Department of Pharmacology and Therapeutics, Faculty of Medicine, Universitas Indonesia, Jakarta, Indonesia

pISSN: 0853-1773 • elSSN: 2252-8083

https://doi.org/10.13181/mji.ed.215620

Med J Indones. 2021;30:87-8

\section{Corresponding author:}

Vivian Soetikno

E-mail: vivian.soetikno@ui.ac.id

\section{REFERENCES}

1. The PLoS Medicine Editors. Best practice in systematic reviews: the importance of protocols and registration. PLoS Med. 2011;8(2):e1001009.

2. Ross JS, Mulvey GK, Hines EM, Nissen SE, Krumholz HM. Trial publication after registration in ClinicalTrials.Gov: a crosssectional analysis. PLoS Med. 2009;6(9):e1000144.

3. Straus S, Moher D. Registering systematic reviews. CMAJ 2010;182(1):13-4.

4. Booth A, Clarke M, Ghersi D, Moher D, Petticrew M, Stewart L. An international registry of systematic-review protocols. Lancet. 2011;377(9760):108-9.

5. Silagy CA, Middleton P, Hopewell S. Publishing protocols of systematic reviews: comparing what was done to what was planned. JAMA. 2002;287(21):2831-4.

6. Loder E, Loder S, Cook S. Characteristics and publication fate of unregistered and retrospectively registered clinical trials submitted to The BMJ over 4 years. BMJ Open. 2018;8:e020037.

7. Irawati Y, Gondhowiardjo TD, Soebono H. Efficacy and safety of platinum chain and gold weight implants for paralytic lagophthalmos: a systematic review. Med J Indones. 2021;30(2):106-15.

8. Irdam GA, Febriyani, Rasyid N, Taher A. A systematic review of intracavernosal injection of mesenchymal stem cells for diabetic erectile dysfunction. Med J Indones. 2021;30(2):96-105.

9. Moher D, Liberati A, Tetzlaff J, Altman DG. Preferred reporting items for systematic reviews and meta-analyses: the PRISMA statement. BMJ. 2009;339:b2535. 